\title{
Bilateral Gluteal Reconstruction with Double Flap Secondary to Biopolymers Injection
}

\author{
Miguel Ángel Sánchez-Morán García, Carlos I. Navarro-Delgadillo, \\ Pamela Sánchez-Morán Pérez, Rogelio Cordova-López, Vanessa Moreno-Diaz, \\ Oscar Pérez-Osorio, Donovan Magaña-Vega, Willian Bautista-Santos \\ Providence Medical Clinic, Ciudad de México, México \\ Email: c_illich@hotmail.com
}

How to cite this paper: Sánchez-Morán García, M.Á., Navarro-Delgadillo, C.I., Sánchez-Morán Pérez, P., Cordova-López, R., Moreno-Diaz, V., Pérez-Osorio, O., Magaña-Vega, D. and Bautista-Santos, W. (2021) Bilateral Gluteal Reconstruction with Double Flap Secondary to Biopolymers Injection. Journal of Biosciences and Medicines, 9, 174-183.

https://doi.org/10.4236/jbm.2021.97016

Received: June 15, 2021

Accepted: July 19, 2021

Published: July 22, 2021

Copyright $\odot 2021$ by author(s) and Scientific Research Publishing Inc. This work is licensed under the Creative Commons Attribution International License (CC BY 4.0).

http://creativecommons.org/licenses/by/4.0/ (c) (i) Open Access

\begin{abstract}
The injection of adjuvant substances for aesthetic purposes is a public health problem, for 40 years this problem has been described throughout our continent, the vast majority of women patients are affected by the infiltration of silicon, mineral oils, automotive oil, methyl methacrylate, cement and various oily substances. This is a 54-year-old female patient who for about 30 years for cosmetic purposes was injected with mineral oil (quantity unknown) in both glutei with the aim of buttock augmentation. Physical examination was observed an important deformity in each buttock, hyperkeratosis with discoloration in both buttocks, loss of bilateral projection, right buttock with a secondary tumor of $22 \mathrm{~cm} \times 11 \mathrm{~cm}$ and left $22 \mathrm{~cm} \times 10 \mathrm{~cm}$, stony appearance, local hyperthermia, painful on manipulation, with diffuse nodular lesions measuring $2 \mathrm{~cm} \times 2 \mathrm{~cm}$, without evidence of loss of continuity that would condition secretion leakage. Surgical planning is based on the very important size of the initial defect that we would have to reconstruct, so that the rotation of two wide-based flaps could guarantee better survival and occlusion of the defect, since the realization of a graft would cause a significant deformity, and the realization of a microsurgical flap in a fibrous tissue would inevitably result in its necrosis. The pathophysiology of the adjuvant disease is extremely complex, therefore it must be addressed by a multidisciplinary group with extensive experience.
\end{abstract}

\section{Keywords}

Gluteal Reconstruction, Biopolymers, Foreign Materials, Biomaterials, Modelants

\section{Introduction}

The injection of adjuvant substances for aesthetic purposes is a public health 
problem, for 40 years this problem has been described throughout our continent, the vast majority of women patients are affected by the infiltration of silicon, mineral oils, automotive oil, methyl methacrylate, cement and various oily substances [1] [2].

The main affected areas are: gluteal, breasts, thighs, genitals, nose, chin and eyelids. It is known that this pathology was exacerbated in our country with the introduction of "Mesotherapy", a means known to deceive patients in search of cosmetic improvement, it is outstanding that $70 \%$ of people who have been infiltrated by adjuvant agents are by professional usurpers, but the other $30 \%$ are medical graduated doctors [3] [4].

Since 1970, a series of articles were published on the specific organic and systemic effects of silicone injection, the results of which are still inconclusive. In 1972, Ortiz Monasterio published the management he gave to 186 patients infiltrated with unknown adjuvant materials in the breast. He concluded that the affected patients could not be managed satisfactorily, stating that prevention is the imperative form of management [5].

The behavior of the infiltrated adjutant agent or their combination has shown a great variety of complications, called multi-organ autoimmune response. The reason why the consultation of a multidisciplinary team is necessary, which must include: plastic surgery anesthesiology, rheumatology, infectology and pneumology [6] [7] [8].

Surgical treatment of adjuvant disease ranges from direct resection and closure to complex reconstructive procedures, including graft harvesting and application, regional flap rotation, and free flaps to try to restore the anatomy as much as possible of the affected region [9].

The objective of presenting the treatment of this patient is to make known that there are different therapeutic options for reconstruction, taking a case as an example that becomes a reconstructive challenge by having practically the entire gluteal region compromised in a bilateral way.

\section{Clinical Case}

After signing the informed consent, in which the need for publication of the case is detailed, omitting the name of the patient, in order to know other options for surgical treatment.

This is a 54-year-old female patient who for about 30 years for cosmetic purposes was injected with mineral oil (quantity unknown) in both gluteus with the aim of a buttock augmentation (Figures 1-5).

Five years after having infiltrated the adjutant agent, it began with a progressive increase in the consistency of both buttocks, presenting diffuse hardness in the sites of greater projection, isolated nodules and intermittent pain. Subsequently, it begins with reorganization of the material, with a predominance in the middle area of both buttocks, with a stony appearance with a progressive change in color and deformation of the area. Similarly, as general symptoms, such as: fever, dyspnea on moderate exertion, asthenia and adynamia. 


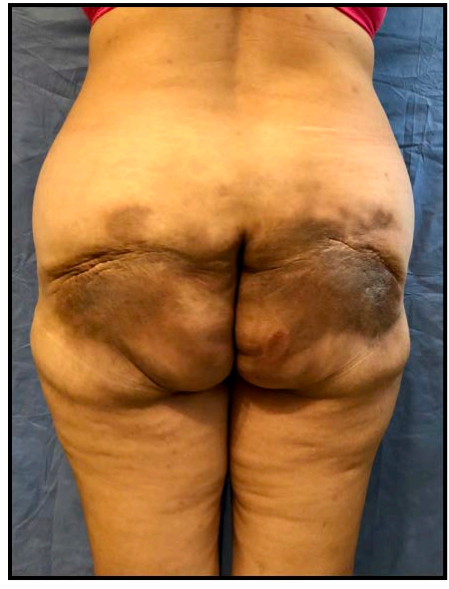

Figure 1. Hyperpigmented areas and skin atrophy.

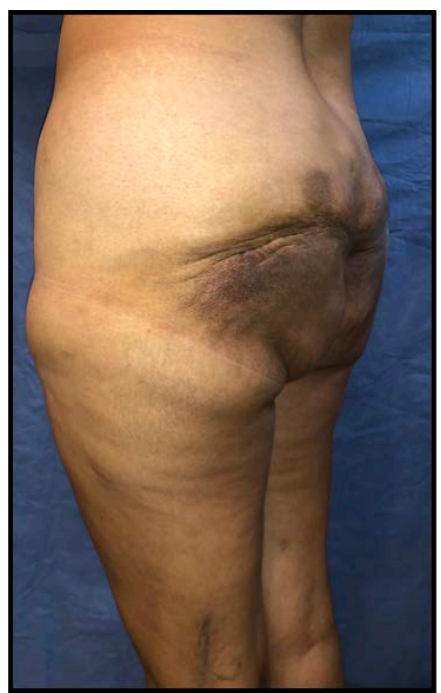

Figure 2. Retractable skin folds.

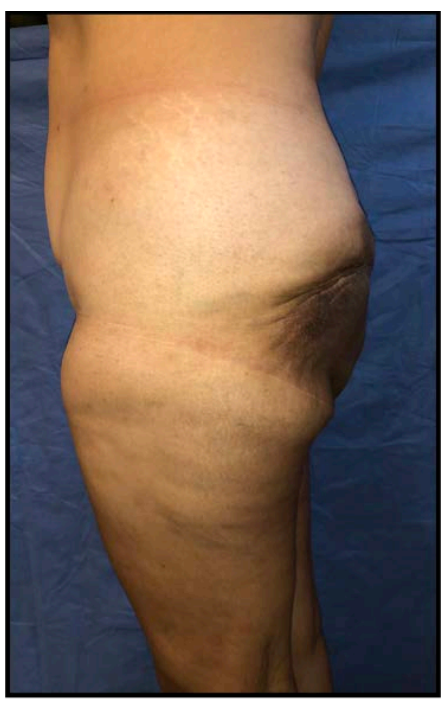

Figure 3. Middle third compromise. 


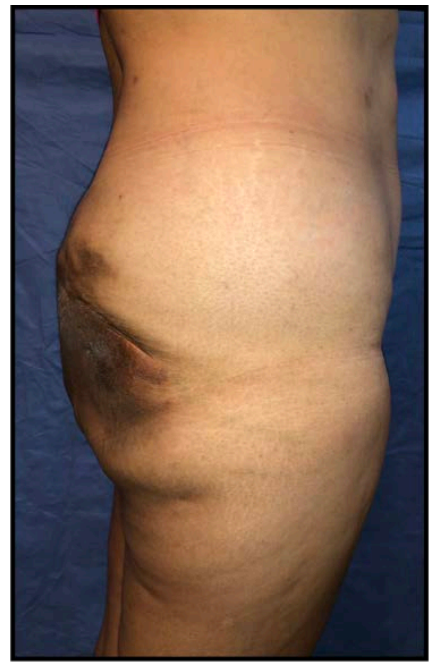

Figure 4. Delimitation of the posterior axillary.

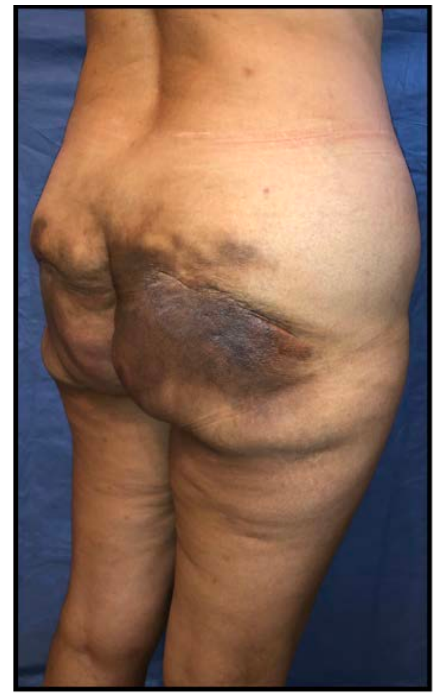

Figure 5. Skin color change with hyperkeratosis.

Physical examination was observed an important deformity in each buttock, hyperkeratosis with discoloration in both buttocks, loss of bilateral projection, right buttock with secondary tumor of $22 \mathrm{~cm} \times 11 \mathrm{~cm}$ and left $22 \mathrm{~cm} \times 10 \mathrm{~cm}$, stony appearance, local hyperthermia, painful on manipulation, with diffuse nodular lesions measuring $2 \mathrm{~cm} \times 2 \mathrm{~cm}$, without evidence of loss of continuity that would condition secretion leakage.

The study protocol included a complete medical history, magnetic resonance imaging, laboratory tests (hematic biometry, blood chemistry, liver function tests, urinalysis), and multidisciplinary evaluations (cardiology, pneumology, nutrition and anesthesiology). The laboratory results did not show significant findings, the blood tests and the evaluations by the specialists did not contraindicate surgical treatment. 
The surgical procedure was planned in two stages (reconstruction of a gluteus by surgery), it consisted of en bloc resection of most of the compromised tissue, which in each gluteus corresponded to the entire middle third, including the greatest amount of disseminated fibrous tissue, and the reconstruction was performed with a double rotation flap with a random vascular pattern.

The surgical procedure was planned in two stages (surgical reconstruction of a gluteus), which consisted in the resection of most of the compromised tissue, corresponding to the entire middle third of each gluteus, including the greatest amount of disseminated fibrous tissue. The reconstruction was performed with a double rotation flap and a random vascular pattern.

The preparatory marking contemplated a $22 \times 11 \times 4 \mathrm{~cm}$ defect in the right gluteus and $22 \times 10 \times 5 \mathrm{~cm}$ in the left gluteus. The hight measurement of the defect was used to measure the rotation bases of both flaps, granting the vascularity of the lumbar area and ipsilateral thigh, so that the resulting scar gives an "italic S" appearance (Figure 6).

In the first surgery, a bloc resection was performed with the aforementioned measures, dissecting up to the fascia of the gluteus maximus. Then, a superior flap with a lateral base and medial vertex was designed, and a lower flap with a medial base and lateral vertex, trying to preserve the thickness and the vascularity of the flaps. The flaps were rotated, observing total occlusion of the defect, sutured in three planes with absorbable suture, and skin with 3-0 nylon, three 1/4 inch penrose drains were placed at each vertex (Figures 7-10).

The second surgery was performed three weeks after the first, when observing an adequate evolution of the first surgery, it is decided to carry out the same planning, avoiding tension in the medial and lateral vertices in order not to compromise blood flow.

The surgery took an average time of 3 hours, performing an initial dissection with a cold scalpel, and later an en bloc resection to the muscle fascia with electrocautery due to the hardness of the tissues and the abundant vasculature.

During the intraoperative period, some satellite lesions are observed on the muscle fascia, which are removed, obtaining viable tissues.

Finally, we proceed to closure in three plans with absobible sutures in the first two and non-absorbable for skin, the skin points will be removed in 2 weeks.

Ambulation was indicated at 24 hours, thromboprophylaxis measures were maintained for 7 days. It is striking that there were no general symptoms in this period of time (fever, asthenia and adynamia). In addition to monitoring the wound, we sought to preserve aesthetics, trying to achieve the greatest possible projection of the buttock.

At 6 months evolution after surgery, the patient presents slight thickening of the upper and lower scars, there is no pain on manipulation, there is an absolute improvement in the quality, tone and color of the skin, including the skin surrounding the initial injury to both buttocks. It is very important to mention that the symptoms shown prior to surgery disappeared, showing a better quality of life (Figure 11). 


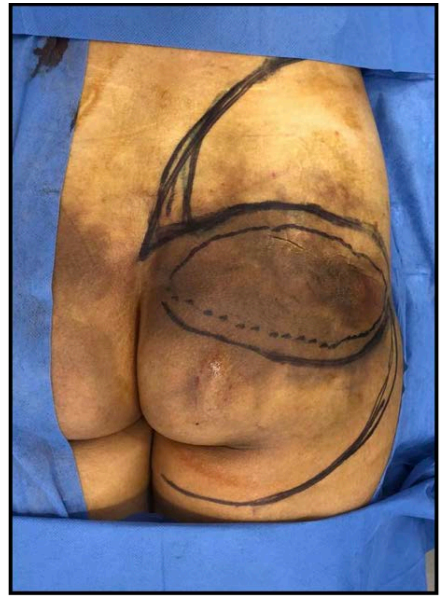

Figure 6. Preoperative marking with a "Double Helix" flap design.

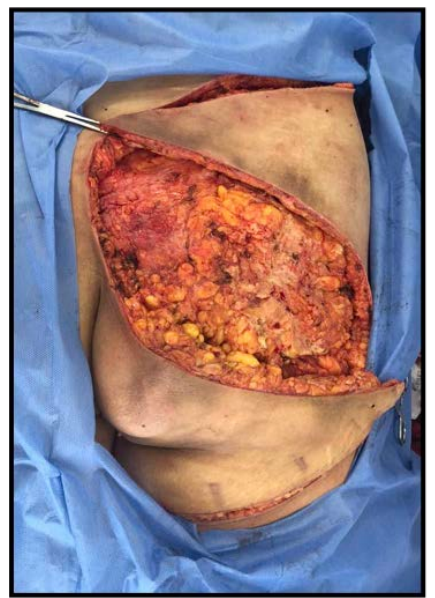

Figure 7. En bloc resection, exposing gluteus maximus fascia and complete flap dissection.

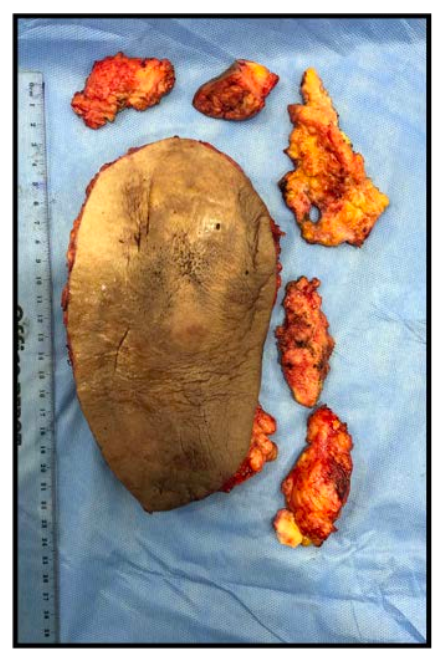

Figure 8. En bloc resected segment with peripheral lesions. 


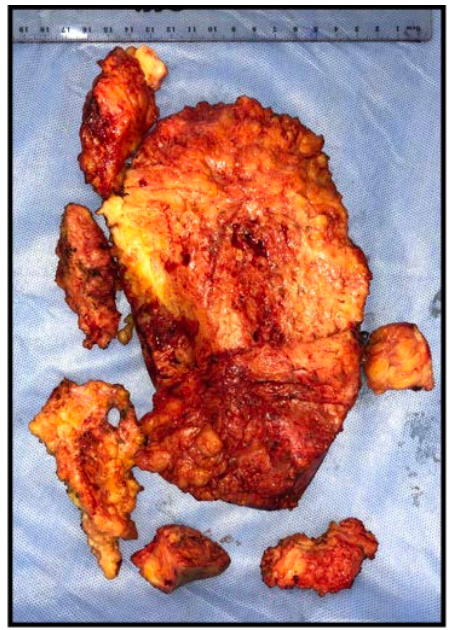

Figure 9. Resected segment of the left gluteus.

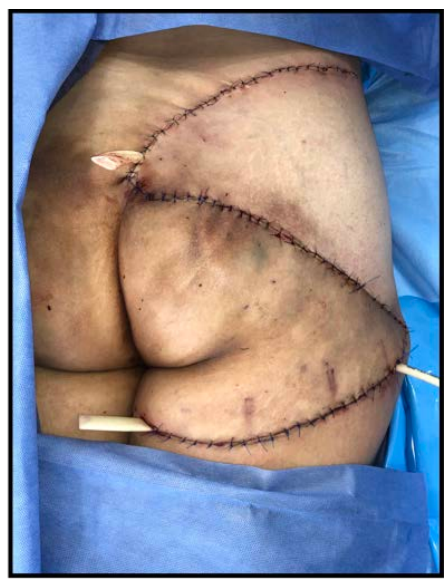

Figure 10. Complete closure of the defect with rotation of flaps and placement of drains.

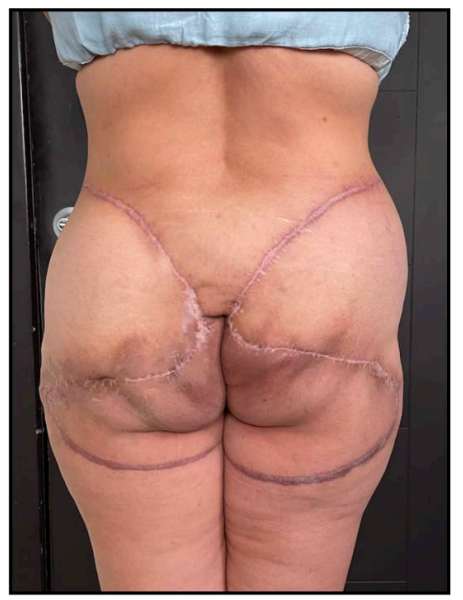

Figure 11. Postoperative at 6 months, slight thickening of the scars. 


\section{Discussion}

The increasingly popular demand to improve body contour, through outpatient procedures, has resulted in the use of different natural or synthetic materials for soft tissue infiltration and molding [10].

Today there are multiple ethical and scientific options with indications and contraindications to perform safe procedures. Complications from infiltrations of foreign materials of doubtful origin, with the aim of improving the contour, continue to be a frequent cause of consultation for our specialty [11].

The use of oily substances occupies a preponderant place in Mexico and Latin American countries, directly associated with the low socioeconomic and cultural level of the patients [12].

In our country there are no series of cases that can correlate the amount and type of material used with the inflammatory or autoimmune response they trigger, so it is very difficult to know the relationship between cause, effect and secondary severity, since we do not know the applied substance, infiltrated volume, solution or mixture of other materials [13].

The deformity that our patient presents years after the mineral oil infiltration is due to the increase in tone caused by the hardening of the tissue, secondary to the large amount of material placed and to the organization over the years of the same. The characteristic of the resected pieces draws our attention due to the strong fibrous and chronic inflammatory reaction of all the tissue, which was ultimately what gave it the stony and retractile appearance in both buttocks.

Surgical planning is based on the very important size of the initial defect that we would have to reconstruct, so that the rotation of two wide-based flaps could guarantee better survival and occlusion of the defect, since the realization of a graft would cause a significant deformity, and the realization of a microsurgical flap in a fibrous tissue would inevitably result in its necrosis.

The evolution of the patient has been satisfactory, mentioning that her quality of life took a 180 degree turn, since the general symptoms previously presented (fever, asthenia, adynamia) disappeared. The pain that conditioned inability to

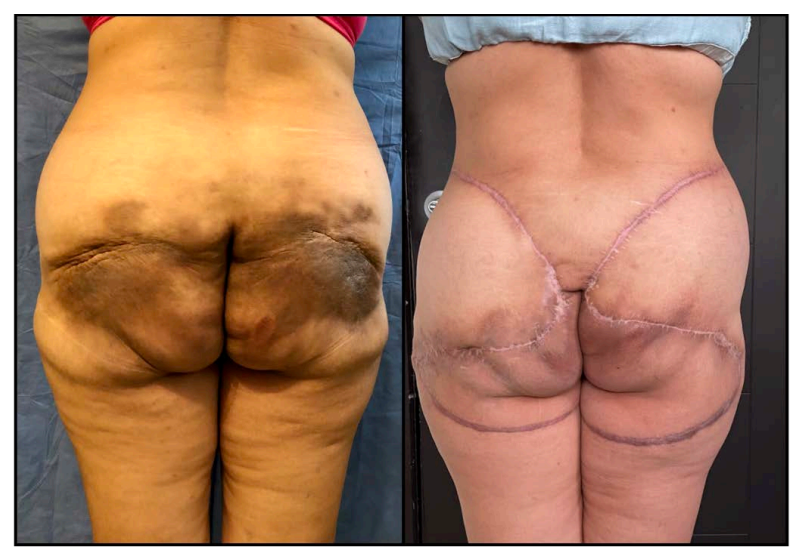

Figure 12. Satisfactory evolution, disappearance of general symptoms, improvement in quality of life and positive psychological impact. 
walk, the pain when sitting and the negative psychological impact are now memories. Although the ability to offer aesthetic resulting scars remains pending, it will be the patient's decision to perform a third surgery (Figure 12).

\section{Conclusions}

The pathophysiology of the adjuvant disease is extremely complex, therefore it must be addressed by a multidisciplinary group with extensive experience.

Before the treatment, the plan must be careful. The en bloc resection continues to be the best therapeutic option. It is worth mentioning that in very severe cases, it is sought to maintain a balance between the resection of most of the compromised tissue without increasing significantly morbidity first of all.

The treatment of this disease, like that of many others in other countries, must be focused on prevention.

\section{Acknowledgements}

To our patient, who throughout the reconstruction process always showed a positive attitude, accepting the publication of this article, with the aim of being able to offer other treatment options to people suffering from this condition. It is of the utmost importance to let them know that in order to us, they are not cured until they are rebuilt.

Thanks to the entire providence medical clinic team, without them we would not have possible to finish the adequate evolution of the patient, medical teamsurgical, nursing and nutrition.

\section{Conflicts of Interest}

The authors declare no conflicts of interest regarding the publication of this paper.

\section{References}

[1] Priego-Blancas, R. (2010) La Enfermedad por modelantes. Un problema de salud pública. Cirugía Plástica, 20, 104.

[2] Miyoshi, K., Miyaoka, T., Kobayashi, Y., Itahura, T., Nishijo, K., Higashitara, M., Shiragami, H. and Ohno, F. (1964) Hypergammaglobulinemia by Prolonged Adjuvancy in Man: Disorder Developed. After Augmentation Mammoplasty. Ijishimpo, 2122, 9-14.

[3] Torres-Gomez, B., Medrano-Ramirez, G., Priego-Blancas, R.B., Pelaez-Ballestas, I. and Burgos-Vargas, R. (2010) Enfermedad por la infiltración de sustancias modelantes con fines estéticos. Cirugía Plástica, 20, 124-132.

[4] Edelman, D.A., Grant, S. and Van Os, W.A.A. (1994) Autoimmune Disease following the Use of Silicone Gel-Filled Breast Implant: A Review of the Clinical Literature. Seminars in Arthritis and Rheumatism, 24, 183-189. https://doi.org/10.1016/0049-0172(94)90074-4

[5] Fernando, O.-M. and Ignacio, T. (1972) Management of Patients with Complications from Injections of Foreign Materials into the Breast. Plastic and Reconstructive Surgery, 50, 42-47. https://doi.org/10.1097/00006534-197207000-00007 
[6] Cabral, A.R., Alcocer-Varela, J., Orozco-Topete, R., Reyes, E., Fernandez-Dominguez, L. and Alarcon-Segovia, D. (1994) Clinical, Histopathological, Immunological and Fibroblast Studies in 30 Patients with Subcutaneous Injections of Modelants including Silicone and Mineral Oils. Revista de Investigacion Clinica, 46, 257-266.

[7] Gutierrez-Salgado, E. and Muñoz-Olvera, R. (2008) Síndrome de embolia grasa secundario a infiltración de polimetilmetacrilato en región glútea. Cirugía Plástica, 18, 78-80.

[8] Gordillo-Hernandez, J., Alegre-Tamez, E., Torres-Baltazar, I., Mendieta-Espinosa, M.J. and Sastré-Ortiz, N. (2013) Multidisciplinary Management of Adjuvant Human Disease by Injection of Modeling Substances. Cirugía Plástica Ibero-Latinoamericana, 39, 269-277. https://doi.org/10.4321/S0376-78922013000300009

[9] Murillo-Godinez, G. (2010) Uso ilicito de modelantes y efectos adversos. Medicina Interna de México, 26, 346-349.

[10] Hage, J.J., Kanhai, R.C., Oen, A.L., et al. (2001) The Devastating Outcome of Massive Subcutaneous Injection of Highly Viscous Fluids in Male-to-Female Transsexuals. Plastic and Reconstructive Surgery, 107, 734-741.

https://doi.org/10.1097/00006534-200103000-00013

[11] Darsow, U., Bruckbauer, H., et al. (2000) Subcutaneous Oleomas Induced by Self-Injection of Sesame Seed Oil for Muscle Augmentation. Journal of the American Academy of Dermatology, 42, 292-294. https://doi.org/10.1016/S0190-9622(00)90144-0

[12] Boo-Chai, K. (1969) The Complications of Augmentation Mammaplasty by Silicone Injection. British Journal of Plastic Surgery, 22, 281-285.

https://doi.org/10.1016/S0007-1226(69)80120-7

[13] Sergott, T.J., Limoli, J.P., Baldwin, C.M. and Laub, D.R. (1986) Human Adjuvant Disease, Possible Autoimmune Disease after Silicone Implantation: A Review of the Literature, Case Studies, and Speculation for the Future. Plastic and Reconstructive Surgery, 78, 104-114. https://doi.org/10.1097/00006534-198607000-00018 